\title{
Analyzing trace gas filaments in the Ex-UTLS by 4D-variational assimilation of airborne tomographic retrievals
}

\author{
Annika Vogel $^{1,2}$, Jörn Ungermann ${ }^{3}$, and Hendrik Elbern ${ }^{1,2}$ \\ ${ }^{1}$ Rhenish Institute for Environmental Research at the University of Cologne, Germany \\ ${ }^{2}$ Institute for Energy and Climate Research - Troposphere (IEK-8), Forschungszentrum Jülich, Germany \\ ${ }^{3}$ Institute for Energy and Climate Research - Stratosphere (IEK-7), Forschungszentrum Jülich, Germany \\ Correspondence to: H. Elbern, he@eurad.uni-koeln.de
}

\begin{abstract}
This case study explores the potential for chemical state analysis at extratropical upper tropospheric - lower stratospheric (Ex-UTLS) height levels with airborne limb-images, assimilated into an advanced spatio-temporal system. The investigation is motivated by the limited capability of both, nadir- and limb-viewing satellite sensors to resolve highly filamented structures, delineated by sharp trace gas gradients on small horizontal and vertical scales. The EURAD-IM (EURopean Air

5 pollution Dispersion - Inverse Model) is applied as assimilation system and designed to extend the flight path confined retrievals from GLORIA (Gimballed Limb Observer for Radiance Imaging of the Atmosphere) to both, larger areas and detailed vertical structures by a tomographic flight pattern. Related potential and limitations of the method are studied with the following features applied: (i) airborne limb-imaging observations of the Ex-UTLS, (ii) spatio-temporal extension by 4-dimensional variational data assimilation, (iii) correlation between ozone and potential vorticity (PV) as an indicator of airmasses and (iv) anisotropic and inhomogeneous horizontal background error correlations in the Ex-UTLS, spreading information towards unobserved regions along PV isopleths. This setup demonstrated substantial improvements to basic approaches in exploring new data on the spatial extend and alignment of airmasses down to small-scale filaments in the Ex-UTLS. Tomographic observations provide detailed insight for reconstructing filamentary foldings along airmass boundaries above the tropopause during this case study.
\end{abstract}

\section{Introduction}

Extratropical upper tropospheric - lower stratospheric $(E x-U T L S)$ height levels are dominated by large gradients of trace gas mixing ratios between stratosphere and troposphere. This highly variable composition introduces a major source of uncertainty in modeling the distributions of atmospheric gases. Riese et al. (2013) showed that even small discrepancies in the strength of isentropic mixing can induce large uncertainties in the atmospheric composition of this area. As atmospheric chemical composition has a strong impact on the radiative transfer, the knowledge of trace gas distributions like ozone or water vapor is crucial for the local radiation budget (e.g., Riese et al., 2014). The radiative effect of trace gases is also influencing the local dynamics by thermal effects. This leads to a direct interaction of chemical, thermal and dynamical aspects (Gettelman et al., 2011). In addition, the processes involved cover a large range of spatial and temporal scales, which makes observations as well as modeling of the Ex-UTLS especially challenging. In terms of in situ observations, long flight tracks covering the Pacific and 
Atmos. Chem. Phys. Discuss., doi:10.5194/acp-2017-308, 2017

Atmospheric

Chemistry

Manuscript under review for journal Atmos. Chem. Phys.

Discussion started: 5 May 2017

(c) Author(s) 2017. CC-BY 3.0 License.

and Physics

Discussions

(c) $\underset{\mathrm{BY}}{\mathrm{B}}$

Atlantic Ocean are performed during the NASA Atmospheric Tomography (ATom) aircraft mission aiming for global chemical climatologies (Prather et al., 2017).

Different types of satellites with nadir- and limb-scanning instruments have been launched to remotely sense distributions of atmospheric trace gases on an operational basis. However, vertical profiles of nadir-looking sensors are too coarse to sample high gradients at the tropopause adequately. Although limb-viewing instruments like MIPAS (Michelson Interferometer for Passive Atmospheric Sounding, e.g., Fischer et al., 2008) and CRISTA (CRyogenic Infrared Spectrometers and Telescopes for the Atmosphere, e.g., Offermann et al., 1999) provide observations in much higher vertical resolution, they cannot resolve small-scale horizontal gradients as they appear along airmass boundaries in this region. To overcome this issue, a new limbimaging approach was developed and realized in the airborne GLORIA (Gimballed Limb Observer for Radiance Imaging of the Atmosphere) instrument for the first time. Its detection technique allows for tomographic observations in an unprecedented spatial resolution which makes it able to resolve resolve filamentary structures in the Ex-UTLS (e.g., Riese et al., 2014; Ungermann et al., 2011).

While novel measurement techniques are able to provide observations of the Ex-UTLS in an adequate resolution, their spatial and temporal coverage is limited (e.g., Riese et al., 2014). Thus, the determination of extension and alignment of different trace gas filaments requires the knowledge of complete atmospheric or chemical states in space and time. Already Danielsen (1968) observed a high correlation between potential vorticity (PV) and ozone mixing ratios along isentropes in the UTLS. This correlation between a dynamical tracer like PV and an atmospheric gas is not obvious due to different sources and sinks (Riishøjgaard and Källen, 1997). Nevertheless, PV shows in practice good performance in identification of airmasses at the UTLS (e.g., Hoskins et al., 1985; Riishøjgaard, 1998)). Furthermore, Douglass et al. (1990) and Lary et al. (1995) demonstrated the potential of combining these meteorological fields with tracer observations to gain an approximation of the chemical state in this region.

Using data assimilation techniques, the information of observations and atmospheric models can be combined in an optimal way (e.g., Lahoz et al., 2010). The generation of an optimized atmospheric state estimation by data assimilation techniques is normally used as input for a prognostic calculation of the numerical model (e.g., Kalnay, 2003). This is expected to increase the forecast skill of this model by reducing the errors induced by the uncertainty of initializing the model (e.g., Rawlins et al., 2007). However, the assimilation result provides detailed information about the atmospheric state at the time of interest. Therefore, it can also be used to analyze atmospheric states and processes from a scientific point of view.

Among a wide range of assimilation techniques, the 4-dimensional variational data assimilation method (4D-var) is an advanced spatio-temporal technique which is widely used in meteorological forecast systems (e.g., Riishøjgaard, 1996; Rawlins et al., 2007; Berre et al., 2015; Bonavita et al., 2016), and increasingly also in chemistry transport modeling (e.g., Elbern et al., 2007; Errera et al., 2008; Emili et al., 2014). Advanced data assimilation techniques are able to obtain information about unobserved regions which are dynamically connected to the locations of observations (Talagrand and Courtier, 1987). As a smoother algorithm, 4D-var propagates signals forward and backward in time to optimize the initial model state with respect to assimilated observations. Thus, it ensures temporal consistency while forcing the model result towards the observations. 
Atmos. Chem. Phys. Discuss., doi:10.5194/acp-2017-308, 2017

Atmospheric

Chemistry

Manuscript under review for journal Atmos. Chem. Phys.

Discussion started: 5 May 2017

(c) Author(s) 2017. CC-BY 3.0 License.

and Physics

Discussions

(c) (i)

The background error covariance matrix $(B E C M)$ of an assimilation system contains the error characteristics of the underlying numerical model. Its main task is to balance the background state with the observations including the observation-errors (e.g., Bannister, 2008; Elbern et al., 2010). Therefore, a realistic representation of model (co-)variances is crucial for a reliable assimilation result as it directly influences the spatial impact of the optimization procedure (e.g., Riishøjgaard, 1998; Weaver and Courtier, 2001). The spatial consistency of a numerical model induces correlations between different elements of the model state vector. Assuming similar spatial error characteristics for highly correlated values, for example within the same airmass, the related forecast errors are also correlated (Riishøjgaard, 1998). In this case the BECM has to consider also covariances between various elements of the model state. This leads to a non-diagonal matrix, the dimension of which increases quadratically with the size of the model state vector. For common numerical models for regional or global meteorological applications the number of elements can become as high as of the order of $10^{12}$, which renders the matrix neither calculable nor explicitly storeable (e.g., Weaver and Courtier, 2001; Elbern et al., 2010). For that reason, the BECM is often implemented as an operator containing the background error (co-)variances.

Riishøjgaard (1998) and Kalnay (2003) indicated, that ensembles may be used to calculate covariances directly via the ensemble spread. Besides the large number of calculations needed to run a representative ensemble, the resulting (co-)variances are highly dependent on the ensemble creation. Additionally, the limited number of realizations induces sampling errors which require additional actions like localization (e.g., Hamill et al., 2001). This creates a need for determining correlations having minimal computational efforts but maximal physical meaning. Bannister (2008) summarized various ways of formulating nonzero error correlations via correlation modeling, which are currently used. One group of methods is based on transformation of the model parameters to control variables having diagonal error characteristics (e.g., Parrish and Derber, 1992). Another set of methods uses spatial transformations to approximate background error correlations. In the diffusion approach introduced by Derber and Rosati (1989) and applied to atmospheric data assimilation by Weaver and Courtier (2001), error correlations are modeled by diffusion of background variances towards neighboring locations. To be able to relate the error correlations to the actual flow, the diffusion coefficient may be increased or reduced anisotropically. Elbern et al. (2010) derived a flow-dependent stretching of the horizontal correlation length for stratospheric chemical applications based on fields of PV.

The objective of this case study is to investigate the potential and limitations for analyzing small-scale filaments in the ExUTLS by chemical data assimilation. Specifically, the following features are developed and evaluated: (i) airborne GLORIA limb-imaging observations providing accurate information down to filamentary structures, (ii) spatio-temporal extension by 4 dimensional variational data assimilation to allow for optimization of unobserved airmasses which are dynamically connected to observations, (iii) correlation between ozone and PV as an indicator of airmasses for model background initialization and (iv) anisotropic and inhomogeneous horizontal background error correlations, spreading information along PV isopleths. This paper is organized as follows: The EURAD-IM assimilation system is described in Sect. 2 including a short description of 4D-var assimilation (2.1), ozone-initialization via PV-correlation (2.2), the implementation of anisotropic background error correlations (2.3) and a short overview of the GLORIA instrument (2.4). The setup of the case-study is described in Sect. 3. Section 4 presents the results of assimilating GLORIA ozone-observations focusing on the distributions of airmasses of different scales. Section 5 concludes this study with a discussion of the results including an outlook. 
Atmos. Chem. Phys. Discuss., doi:10.5194/acp-2017-308, 2017

Atmospheric

Manuscript under review for journal Atmos. Chem. Phys.

Chemistry

Discussion started: 5 May 2017

(c) Author(s) 2017. CC-BY 3.0 License.

$\frac{\text { and Physics }}{\text { Discussions }}$

(c) (i)

\section{Assimilation system}

This section describes the numerical spatio-tempoal assimilation system EURAD-IM (EURopean Air pollution DispersionInverse Model) and the airborne instrument GLORIA.

The EURAD-IM model system performs chemical data assimilation of the lower atmosphere with high spatial and temporal resolution. It combines four-dimensional variational data assimilation (4D-var) with a state-of-the-art chemistry transport model (CTM, e.g., Elbern et al., 2007). The EURAD-IM is an Eulerian multiscale CTM providing prognostic calculations of a large number of atmospheric gases and aerosols taking into account dynamical as well as chemical effects (Hass and Memmesheimer, 1995). The model domain is created by a Lambert conformal projection. The horizontal grid is structured in an Arakawa-C grid stencil and the vertical model layers are defined by terrain-following $\sigma$-coordinates.

Various types of atmospheric-chemical observations can be assimilated in the EURAD-IM model system. In this study, retrieved ozone-mixing ratios from the airborne remote-sensing instrument GLORIA were used. In addition to observational data, the chemical data assimilation system requires fields of meteorological parameters as well as information on emissions for the entire assimilation window. The meteorology for the EURAD-IM is calculated by the numerical weather prediction model WRF-ARW (Advanced Research WRF, e.g., Skamarock et al., 2005).

\subsection{D-variational data assimilation}

4D-var is an advanced spatio-temporal data assimilation technique which offers the ability to optimize parameters in space and time. The optimality of its solution is analyzed by assuming Gaussian error characteristics of observations and model forecasts applied to the Bayesian theorem (Lorenc, 1988).

After some algebraic manipulation, the cost function of 4D-var can be written as follows:

$J\left(\boldsymbol{x}_{0}\right)=\frac{1}{2} \cdot\left(\boldsymbol{x}_{0}-\boldsymbol{x}_{0}^{b}\right)^{T} \mathbf{B}^{-1}\left(\boldsymbol{x}_{0}-\boldsymbol{x}_{0}^{b}\right)+\frac{1}{2} \cdot \sum_{i=0}^{n_{\text {time }}}\left[\left(\mathcal{H}\left(\mathcal{M}_{0, i}\left(\boldsymbol{x}_{0}\right)\right)-\boldsymbol{y}_{i}\right)^{T} \mathbf{R}^{-1}\left(\mathcal{H}\left(\mathcal{M}_{0, i}\left(\boldsymbol{x}_{0}\right)\right)-\boldsymbol{y}_{i}\right)\right]$,

were $\boldsymbol{y}_{i}$ is a vector containing all observations valid for a model timestep $t_{i}$ within the assimilation window $\left[t_{0}, t_{n_{\text {time }}}\right]$. The optimization parameters are trace gas concentrations of the initial model state $\boldsymbol{x}_{0}$, starting from the initial background state $\boldsymbol{x}_{0}^{b}$ for the first iteration. The nonlinear model operator $\mathcal{M}_{0, i}$ represents the EURAD-IM chemical transport model including the whole set of featured atmospheric and chemical processes, which is described in Elbern et al. (2007) in more detail. The nonlinear transformation between model state and observation state is included in the observation operator $\mathcal{H}$. Both information sources contributing to the cost function are weighted by their error covariance matrices $\mathbf{B}$ and $\mathbf{R}$ for background and observations, respectively.

The gradient of the cost function with respect to the initial model state $\boldsymbol{x}_{0}$ reads:

$$
\nabla_{\boldsymbol{x}_{0}} J\left(\boldsymbol{x}_{0}\right)=\mathbf{B}^{-1}\left(\boldsymbol{x}_{0}-\boldsymbol{x}_{0}^{b}\right)+\sum_{i=0}^{n_{\text {time }}}\left[\mathbf{M}_{0, i}^{T} \mathbf{H}^{T} \mathbf{R}^{-1}\left(\mathcal{H}\left(\mathcal{M}_{0, i}\left(\boldsymbol{x}_{0}\right)\right)-\boldsymbol{y}_{i}\right)\right],
$$

with $\mathbf{M}_{0, i}$ and $\mathbf{H}$ being the tangential linearizations of forward model and observation operator at $\boldsymbol{x}_{0}$ and $\mathcal{M}_{0, i}\left(\boldsymbol{x}_{0}\right)$, respectively. A detailed description of the theoretical derivation can for example be found in Lorenc (1988) and Kalnay (2003). 
Atmos. Chem. Phys. Discuss., doi:10.5194/acp-2017-308, 2017

Manuscript under review for journal Atmos. Chem. Phys.

The 4D-var assimilation algorithm in EURAD-IM is implemented in a preconditioned form according to Courtier (1997):

$$
\begin{aligned}
& J\left(\boldsymbol{v}_{0}\right)=\frac{1}{2} \cdot \boldsymbol{v}_{0}{ }^{T} \boldsymbol{v}_{0}+\frac{1}{2} \cdot \sum_{i=0}^{n_{\text {time }}}\left[\left(\mathcal{H}\left(\mathcal{M}_{0, i}\left(\mathbf{B}^{\frac{1}{2}} \boldsymbol{v}_{0}\right)\right)-\boldsymbol{d}_{i}\right)^{T} \mathbf{R}^{-1}\left(\mathcal{H}\left(\mathcal{M}_{0, i}\left(\mathbf{B}^{\frac{1}{2}} \boldsymbol{v}_{0}\right)\right)-\boldsymbol{d}_{i}\right)\right] \\
& \nabla_{\boldsymbol{v}_{0}} J\left(\boldsymbol{v}_{0}\right)=\boldsymbol{v}_{0}+\sum_{i=0}^{n_{\text {time }}}\left[\mathbf{B}^{\frac{T}{2}} \mathbf{M}_{0, i}^{T} \mathbf{H}^{T} \mathbf{R}^{-1}\left(\mathcal{H}\left(\mathcal{M}_{0, i}\left(\mathbf{B}^{\frac{1}{2}} \boldsymbol{v}_{0}\right)\right)-\boldsymbol{d}_{i}\right)\right],
\end{aligned}
$$

where the optimization variable $\boldsymbol{v}_{0}:=\mathbf{B}^{-\frac{1}{2}} \boldsymbol{d} \boldsymbol{x}_{0}=\mathbf{B}^{-\frac{1}{2}}\left(\boldsymbol{x}_{0}-\boldsymbol{x}_{0}^{b}\right)$ and $\boldsymbol{d}_{i}:=\boldsymbol{y}_{i}-\mathcal{H}\left(\mathcal{M}_{0, i}\left(\boldsymbol{x}_{0}^{b}\right)\right)$ are defined to avoid the 5 calculation of the inverse background error covariance matrix $\left(\mathbf{B}^{-1}\right.$ or $\left.\mathbf{B}^{-\frac{1}{2}}\right)$, which is computationally prohibitive for highdimensional optimization problems. For common numerical weather prediction or chemistry transport models, the number of state elements can reach the order of $10^{6}$ which makes the BECM being a $10^{6} \times 10^{6}$ matrix (e.g., Weaver and Courtier, 2001).

The limited-memory BFGS (L-BFGS, e.g., Liu and Nocedal, 1989) is applied to perform the iterative minimization of the preconditioned costfunction and its gradient given by Eq. (3). The minimization is stopped after a convergence criterion is reached. Additionally, the number of iterations is limited for computational reasons.

\subsection{Ozone-initialization via PV-correlation}

Although the general correlation between PV and ozone has been well known for decades, the concrete factor for relating ozone to PV has to be approximated for each specific situation. For this study, MLS (Microwave Limb Sounder, e.g., Waters et al., 2006) satellite observations have been used to determine the correlation factor between PV and ozone. MLS profiles for Europe on 26 September 2012 are available around 12 UTC. Model ozone concentrations were initialized using different correlation factors at the initial time 6 UTC. Calculating forward to 12 UTC makes the model states comparable to the MLS observations. The correlation factor of

$\left[O_{3}\right]=40 \frac{\mathrm{ppbv}}{\mathrm{pvu}} \cdot P V$,

was found to fit best and was used for the background initialization later. Figure 1 shows the results for initializing the ozone model concentration with this correlation factor. The selected model layer is referring to the observed pressure level of 170 $\mathrm{hPa}$.

The high correlation between ozone and PV is only valid for stratospheric conditions and loosing validity below the dynamical tropopause. Thus, the initial ozone fields below these altitudes should be left constant. Taking the lowest height of GLORIA observations into account, a lower limit for initialization with PV was set to $6 \mathrm{~km}$ height. With the chosen correlation factor

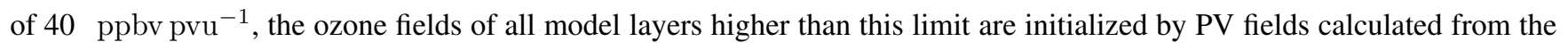
meteorological forecast.

\subsection{Anisotropic background error correlations}

4D-var should be able to account for anisotropic and inhomogeneous spatial correlations of the model state, as controlled by dynamical processes. Following Weaver and Courtier (2001), the EURAD-IM assimilation system makes use of a diffusion approach to account for spatial correlations of background errors. The underlying idea is to split the background error covariance 
Atmos. Chem. Phys. Discuss., doi:10.5194/acp-2017-308, 2017

Manuscript under review for journal Atmos. Chem. Phys.

Discussion started: 5 May 2017

(C) Author(s) 2017. CC-BY 3.0 License.
Atmospheric

Chemistry

and Physics

Discussions

(c) $\underset{\mathrm{BY}}{\mathrm{P}}$

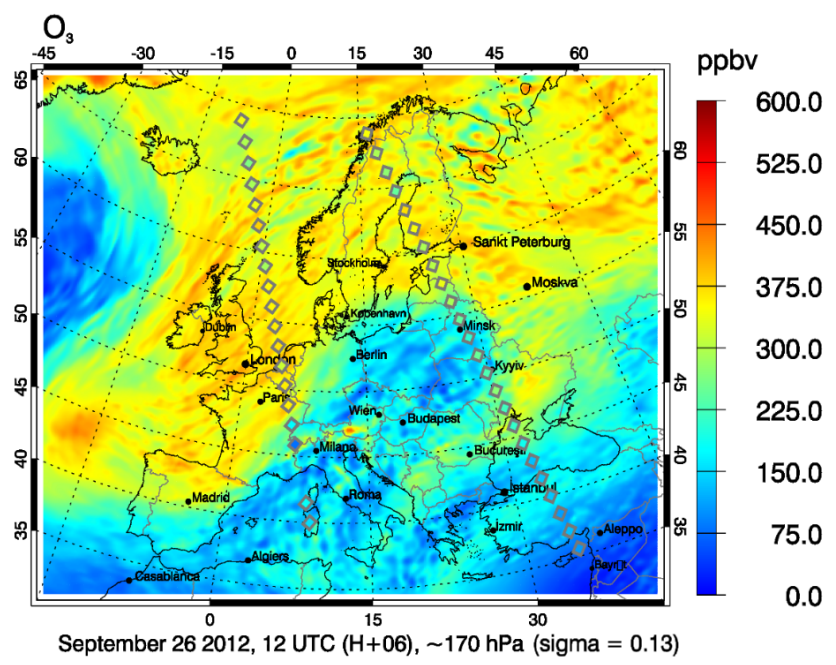

Figure 1. CTM-forecast on 26 September 2012, 12 UTC for initializing the ozone concentration at 6 UTC with a correlation factor of 40 ppbv $\mathrm{pvu}^{-1}$, which fitted best to MLS observations at this time. Ozone concentrations of model forecast, overplotted by MLS observations (color coded diamonds) referring to a height approximately $170 \mathrm{hPa}$ are shown (coded by colors).

matrix $\mathbf{B}$ into a few components, each given by a single operator:

$\mathbf{B}=\boldsymbol{\Sigma} \mathbf{C} \boldsymbol{\Sigma}=\left(\boldsymbol{\Sigma} \Lambda \mathbf{L}^{\frac{1}{2}} \mathbf{W}^{-\frac{1}{2}}\right)\left(\mathbf{W}^{-\frac{T}{2}} \mathbf{L}^{\frac{\mathrm{T}}{2}} \boldsymbol{\Lambda} \boldsymbol{\Sigma}\right)$

were $\boldsymbol{\Sigma}$ is a diagonal matrix including standard deviations of each element of the model state vector. The correlation matrix $\mathbf{C}$ contains the spatial correlations between the elements of the state vector. $\boldsymbol{\Lambda}$ provides the normalization of the diffusion and $\mathbf{W}$ considers volume-related scaling. The spatial correlation $\mathbf{L}$ is implemented by applying information-diffusion:

$\frac{\partial \phi}{\partial t}=\nabla[\kappa \cdot \nabla \phi]$

$\frac{\partial \phi}{\partial t}$ is the local temporal derivative of a quantity $\phi$ and $\nabla$ denotes the differential operator in three spacial directions. The diffusion coefficient $\kappa$ controls the amount of diffusion via a correlation length $l$.

Most of the numerical weather prediction systems assume the horizontal background error correlations to be isotropic and homogeneous (Bannister, 2008), which would lead to a constant coefficient $\kappa$. However Elbern et al. (2010) introduced a two-dimensional flow-dependency for the diffusion approach. Assuming PV to be a passive tracer, similar PV values can be related to homogeneous airmasses in the UTLS (e.g., Hoskins et al., 1985; Danielsen et al., 1987). Thus, horizontal gradients of PV are used as indicator of airmass boundaries and consequently decreased spatial correlations of chemical composition. This approach was implemented by multiplying the horizontal component of the constant diffusion coefficient $\bar{\kappa}_{h}$ with a PVdependent coordinate stretching tensor $\mathbf{S}\left(\kappa_{h}=\bar{\kappa}_{h} \cdot \mathbf{S}\right)$. It creates a flow-dependent stretching of the horizontal correlation 
Atmos. Chem. Phys. Discuss., doi:10.5194/acp-2017-308, 2017

Manuscript under review for journal Atmos. Chem. Phys.

Discussion started: 5 May 2017

(c) Author(s) 2017. CC-BY 3.0 License.

(c) (i)
Atmospheric

Chemistry

and Physics

Discussions (a)

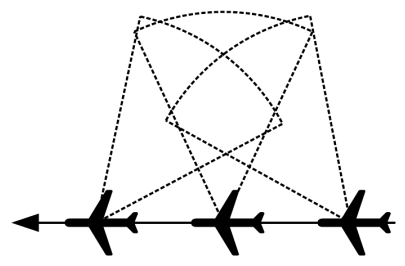

(b)

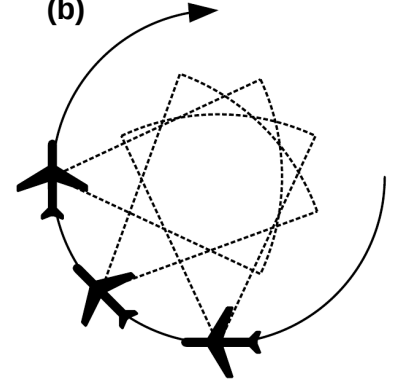

Figure 2. Horizontal illustration of tomographic observations using limb-imaging for a straight (a) and a closed (b) flight path (solid line). The overlap of areas covered by target points (framed dotted lines) was taken from a limb-imaging instrument mounted on an aircraft (according to Ungermann et al., 2011).

based on local stretching $\left(s_{\text {stre }}\right)$ and compression $\left(s_{\text {comp }}\right)$ factors:

$\mathbf{S}=\mathbf{T} \widetilde{\mathbf{S}} \mathbf{T}^{\mathbf{T}}=\left(\begin{array}{cc}\cos (\alpha) & \sin (\alpha) \\ -\sin (\alpha) & \cos (\alpha)\end{array}\right)\left(\begin{array}{cc}s_{\text {comp }} & 0 \\ 0 & s_{\text {stre }}\end{array}\right)\left(\begin{array}{cc}\cos (\alpha) & -\sin (\alpha) \\ \sin (\alpha) & \cos (\alpha)\end{array}\right)$

Parameter $\alpha$ is the angle rotating the coordinate system perpendicular to the local horizontal gradient in PV. The local amount of stretching $c_{\mathrm{S}}$ is defined by the absolute gradient in PV, normalized by its maximum on the model layer. With $s_{\mathrm{MIN}}$ and $s_{\mathrm{MAX}}$ being predefined limitations for correlation compression- and stretching-factors, the local stretching factors can be calculated:

$s_{\mathrm{comp}}=\left[1+c_{\mathrm{s}} \cdot\left(s_{\mathrm{MIN}}^{-1}-1\right)\right]^{-1} \quad, \quad s_{\mathrm{stre}}=1+c_{\mathrm{s}} \cdot\left(s_{\mathrm{MAX}}-1\right)$

For a detailed description of this approach see Elbern et al. (2010).

\subsection{GLORIA limb-imaging sensor}

The airborne GLORIA instrument consists of a Fourier transform spectrometer, which is sensitive to atmospheric radiation in the mid-infrared region. In the observed spectral range between $780 \mathrm{~cm}^{-1}$ and $1400 \mathrm{~cm}^{-1}$, it is able to detect signals from a large set of atmospheric parameters, including temperature, various trace gases like ozone, water vapor and nitric acid as well as subvisible clouds. The concept of the instrument is exposed in Riese et al. (2014). A more detailed description of its tomographic observations can be found in Ungermann et al. (2011) and Kaufmann et al. (2015). Technical details are given by Ungermann et al. (2015).

A new limb-imaging approach was realized in this instrument for the first time. In this approach, a two dimensional image is taken instead of a single value. This results in two main advantages: Firstly, a limb imager observes a complete vertical profile simultaneously, which avoids the temporal delay of vertical scanning limb sounders. Secondly, the area covered horizontally by each image gives a horizontal distribution at each measurement time.

GLORIA is able to rotate the instrument's optics between $45^{\circ}$ and $135^{\circ}$ relative to the flight direction, as shown in Fig. 2 . The resulting overlaps give the possibility to retrieve three dimensional information about the area covered. Flying a closed path 
Atmos. Chem. Phys. Discuss., doi:10.5194/acp-2017-308, 2017

Manuscript under review for journal Atmos. Chem. Phys.

Discussion started: 5 May 2017

(c) Author(s) 2017. CC-BY 3.0 License.
Atmospheric

Chemistry

and Physics

Discussions

(c) $\underset{\mathrm{BY}}{(i)}$

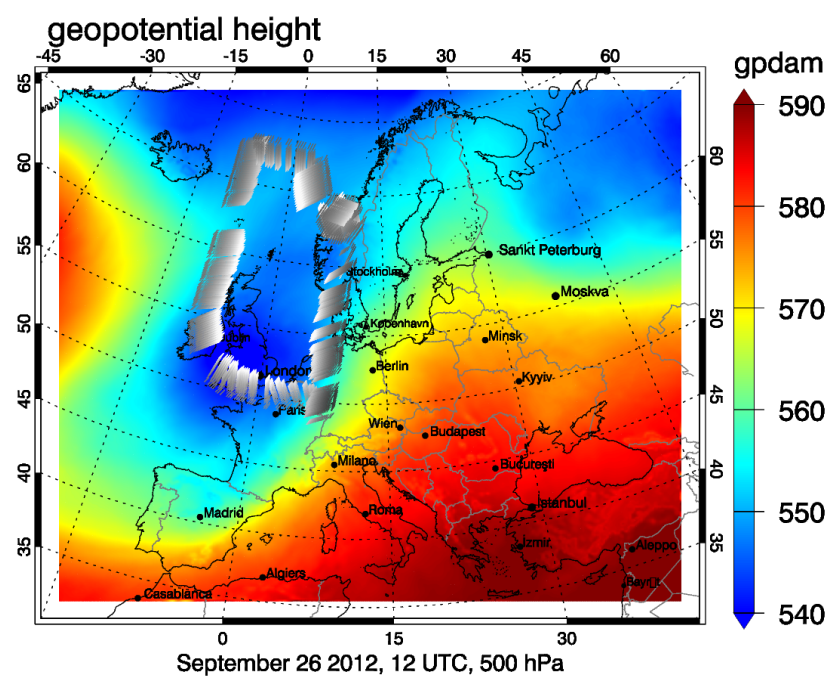

Figure 3. Synoptic situation and locations of GLORIA observations on 26 September 2012. The colors show the geopotential height at 500 $\mathrm{hPa}$ as forecasted by WRF for 12 UTC. The locations of the observations are given in gray, coded by their tangent altitude (light: $6 \mathrm{~km}$, dark: $14 \mathrm{~km})$.

increases the overlapping area as well as the number of overlapping images (Fig. 2b). This idealized closed tomography results in an optimal horizontal resolution in every direction and can be considered as three dimensional tomographic observation. Consequently, the assumption of horizontal homogeneity in the cross-flight direction typically needed for the retrieval process is not needed anymore, making the instrument suitable for detecting high horizontal gradients in the UTLS. Ungermann et al.

5 (2011) showed that GLORIA is able to retrieve three dimensional fields, having resolutions of about $300 \mathrm{~m}$ vertically and down to $30 \mathrm{~km}$ horizontally.

\section{Description of the case study}

Ozone retrievals from the flight on 26 September 2012 as part of the TACTS (Transport And Composition in the UTLS) / ESMVal (Earth System Model VALidation) campaign on the research aircraft HALO (High Altitude and LOng range) are used.

10 For this study, the observations while GLORIA was pointing perpendicular to the flight direction are chosen representatively for the whole dataset (compare e.g., Ungermann et al., 2015).

On this day, the synoptic situation was dominated by a trough over north-western Europe, as it can be seen in Fig. 3. The horizontal orientation of the trough axis in the upper troposphere was in the south-west to north-east direction. Its extension covered Scandinavia in the north as well as Spain and Portugal in the south, with its center located above the British Isles.

15 This caused a basically meridional atmospheric circulation over Europe and the North Atlantic. During the day, the trough was almost stationary with a small eastward moving component. Thus, the location of the observations relative to the trough can approximately be described looking the situation at 12 UTC (Fig. 3). 
Atmos. Chem. Phys. Discuss., doi:10.5194/acp-2017-308, 2017

Atmospheric

Manuscript under review for journal Atmos. Chem. Phys.

Chemistry

Discussion started: 5 May 2017

(c) Author(s) 2017. CC-BY 3.0 License.

$\frac{\text { and Physics }}{\text { Discussions }}$

(c) (i)

Starting from southern Germany at around 6 UTC, the research aircraft HALO flew westbound towards the center of the trough over the British Isles. After turning north over the Atlantic and east towards Norway, a hexagonal flight pattern with a diameter of about $400 \mathrm{~km}$ (Riese et al., 2014) was flown next to the coast of Norway. Afterwards, the aircraft turned homebound. Tangent heights of GLORIA during this flight lay roughly between $6 \mathrm{~km}$ and $14 \mathrm{~km}$ varying with the airplanes altitude.

In order to be able to simulate observed structures in these UTLS altitudes, the upper boundary of EURAD-IM was lifted from $100 \mathrm{hPa}$ to $50 \mathrm{hPa}$. Additionally, the vertical resolution around the UTLS height levels was increased to $600 \mathrm{~m}$ for the first investigation (Sect. 4.1). For the small-scale analysis in Sect. 4.2, the vertical model structure was further refined to $300 \mathrm{~m}$ in the UTLS. Due to the limited time range of available observations on 26 September 2012 being approximately between 6:30 UTC and 15:30 UTC, the assimilation window was defined to be 10 hours from 6:00 UTC to 16:00 UTC. The meteorological forecast generated by WRF-ARW was initialized on 26 September 2012, 00 UTC with interpolated fields of GFS (Global Forecast System) reanalysis data (e.g., Kalnay et al., 1996).

Analogous to the lower boundary of PV-initialization of ozone, the anisotropy is used for all layers being higher than $6 \mathrm{~km}$ above sea level. With an average horizontal correlation length of $\overline{l_{\mathrm{h}}}=75 \mathrm{~km}$, the limits for the maximal amount of stretching and compression were set to $s_{\mathrm{MAX}}=9$ and $s_{\mathrm{MIN}}=s_{M A X}{ }^{-1}=\frac{1}{9}$. This leaves the total area of influence unchanged compared to the isotropic reference. Due to a quadratic use of the anisotropic correlation length $l_{\mathrm{h}}$ in the correlation diffusion coefficient, it ranges from $\min \left(l_{\mathrm{h}}\right)=\frac{1}{3} .75 \mathrm{~km}=25 \mathrm{~km}$ to $\max \left(l_{\mathrm{h}}\right)=3.75 \mathrm{~km}=225 \mathrm{~km}$ for maximal PV gradients.

\section{Results}

Focusing on different spatial scales, the description and evaluation of the results addresses synoptic scale features in Sect. 4.1 followed by a more detailed analysis of filamentary structures in Sect. 4.2.

\section{$20 \quad 4.1$ Assimilation using flow-dependent correlations}

This section demonstrates the beneficial effects of the combination of PV-ozone correlation and PV guided covariance modeling for chemical state analysis in the Ex-UTLS.

Ozone observations from GLORIA on 26 September 2012 are assimilated using the PV-dependent adaptation of the EURADIM system. In the presence of a trough over western Europe, the modeled and observed ozone concentrations show much higher values in this region which can be related to stratospheric conditions in $11 \mathrm{~km}$ height. Regarding synoptic-scale structures, the background model state initialized by PV in Fig. 4 is quantitatively in good agreement with the observations. This demonstrates that the meteorological forecast by WRF captures the position of the trough adequately.

A comparison between the assimilation results with isotropic and flow-dependent covariance modeling in about $11 \mathrm{~km}$ height and related observations from GLORIA is shown in Fig. 5. A negative bias between the observations and the model background state caused a reduction of the analysis state in most of the observed regions (Fig. 5c). The highest increment can be found in the northern part of Portugal and Spain although this region was not observed directly. This is caused by the presence of a jet stream along the edge of the trough over Europe. This leads to fast advection of air from Portugal and Spain 
Atmos. Chem. Phys. Discuss., doi:10.5194/acp-2017-308, 2017

Manuscript under review for journal Atmos. Chem. Phys.

Discussion started: 5 May 2017

(c) Author(s) 2017. CC-BY 3.0 License.
Atmospheric

Chemistry

and Physics

Discussions

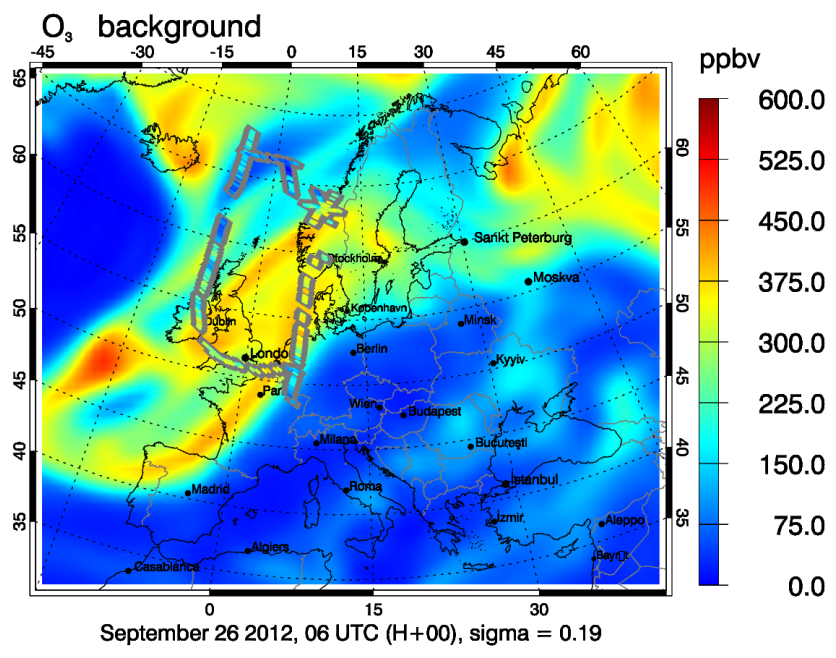

Figure 4. Background state on 26 September 2012, 6 UTC at approximately $11 \mathrm{~km}$ altitude. Concentrations from GLORIA retrievals for this height are overplotted coded by colors (gray-framed). The tomography at the coast of Norway appears as star-shaped observations. Note the time differences between observations (approx. taken between 6:30 and 15:30 UTC) and model (shown are results for 6:00 UTC).

in north-east direction towards central Europe, connecting airmasses observed above the North Sea and western Germany dynamically to this region. The temporal retention of chemical and physical consistency by $4 \mathrm{D}$-var is able to transport the signal of these observations taken between 14 UTC and 15 UTC backward in time to its origin at 6 UTC.

East of Iceland, an airmass of relatively low ozone concentrations was observed twice. Because of the ozone-initialization via

$5 \mathrm{PV}$, the modeled boundary of the ozone-filament is related to a significant gradient in PV. The resulting stretch of the horizontal correlation in the southwest-northeast direction leads to a connection of the two observed areas in the analysis increment (Fig. $5 \mathrm{c}$ ). As it can be seen in the analysis (Fig. 5b), correcting the modeled ozone towards lower concentrations affects large parts of the tropospheric airmass in this height. This becomes possible by the dynamical consistency between ozone initialization and background error correlation, both based on PV fields. Thus, its shape is nearly conserved with the ozone mixing ratio being reduced from about $100 \mathrm{ppbv}$ in the background state to less than $50 \mathrm{ppbv}$ in the analysis.

\subsection{Small-scale analysis of tomographic observations}

At the coast of Norway, the information about an airmass boundary indicated by the tomographic observation is stretched according to a local horizontal gradient in the forecasted PV field. Thus, a filamentary airmass elongated in the southwestnortheast direction was identified by the anisotropic analysis (Fig. 5b) which was not visible in the isotropic case (Fig. 5a). This increased the horizontal gradient along this axis to concentrations between 75 ppbv and 400 ppbv within $85 \mathrm{~km}$ distance.

The initialization of ozone fields around the Ex-UTLS by PV provides a dynamically consistent initial guess to start the assimilation. As filamentary disturbances are influenced by local mixing and dispersion processes which may not be represented 
Atmos. Chem. Phys. Discuss., doi:10.5194/acp-2017-308, 2017

Manuscript under review for journal Atmos. Chem. Phys.

Discussion started: 5 May 2017

(c) Author(s) 2017. CC-BY 3.0 License.
Atmospheric

Chemistry

and Physics

Discussions

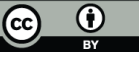

(a) isotropic analysis

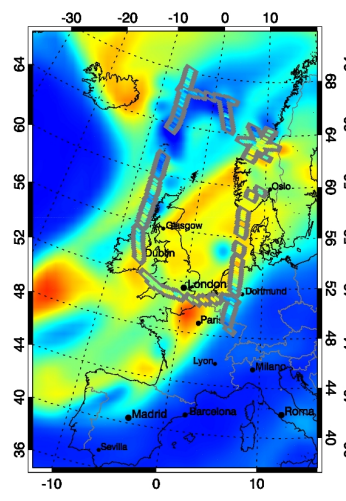

(b) flow-dependent analysis

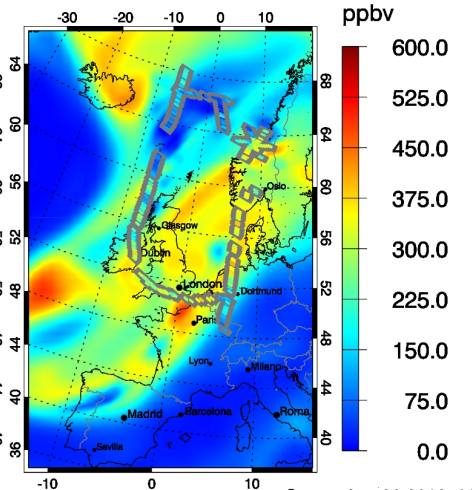

(c) flow-dependent analysis increment

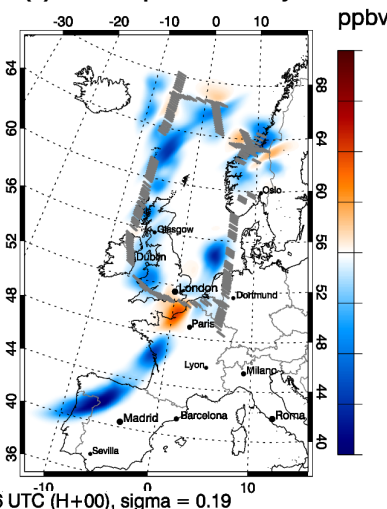

(d) flow-dependent - isotropic analysis
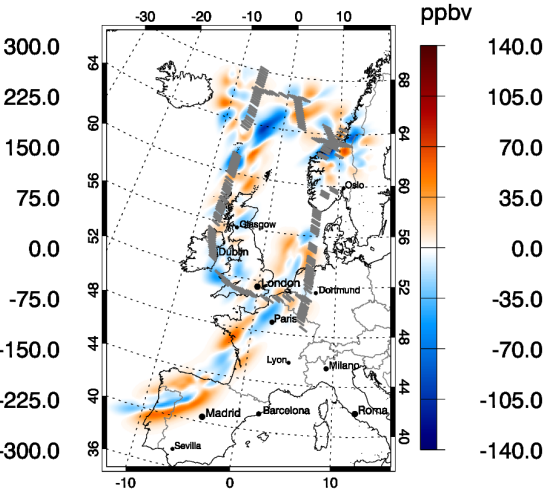

Figure 5. Comparison between isotropic analysis (a) and flow-dependent analysis (b), flow-dependent analysis increment (analysis minus background, c) as well as flow-dependent minus isotropic analysis (d) on 26 September 2012, 6 UTC for a model level approximately at 11 km altitude. Plotting conventions as in Fig. 4
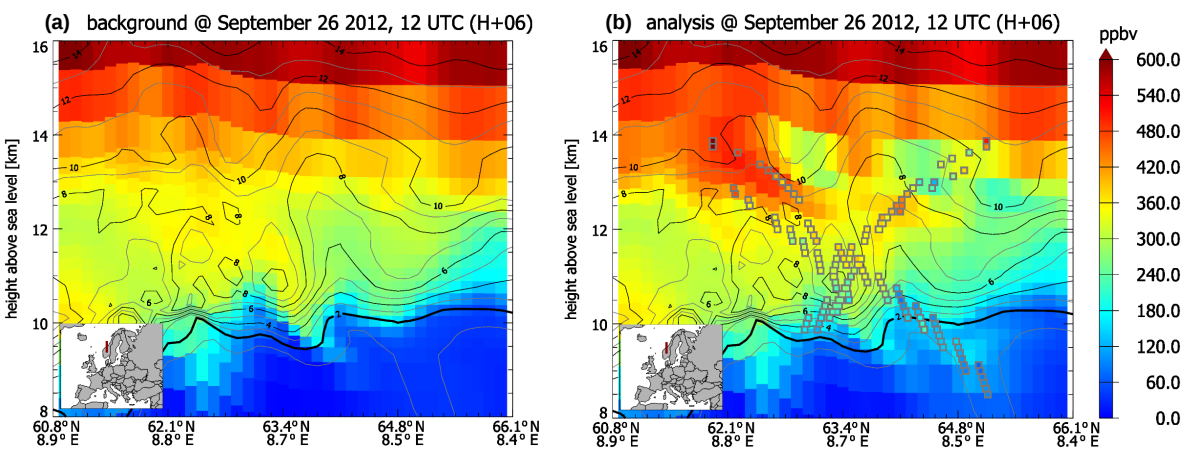

Figure 6. Vertical cross-section of background (a) and analysis state (b) at 12 UTC as well as hexagonal observations. The cross-section is orientated in north-south direction as indicated by the inlay. Ozone concentrations of analysis (blocked sections due to grid resolution) and observations are coded by colors. The forecasted PV field is indicated by isolines (numbers in PVU). Please note the time differences between hexagonal observations (approx. taken between 11:30 and 12:30 UTC) and model (shown are results for 12:00 UTC).

well in the meteorological forecast, these structures cannot be directly related to the predicted PV fields. However, the results of Sect. 4.1 show the ability of the analysis to reproduce small-scale variability indicated by GLORIA observations.

The high density of tangent points of the closed tomographic observation by GLORIA encourage a further decreased vertical thickness of the model layers in the UTLS. Therefore, the vertical resolution was again increased to about $300 \mathrm{~m}$ between 10 and $13 \mathrm{~km}$ height where most of the observations of GLORIA were located. The rest of the assimilation procedure was left unchanged.

For small-scale structures observed by GLORIA at the coast of Norway, the vertical distribution of background and analysis can be found in Fig. 6. A vertical cross-section through the center of the hexagon in north-south direction is shown. In this 
Atmos. Chem. Phys. Discuss., doi:10.5194/acp-2017-308, 2017

Atmospheric

Manuscript under review for journal Atmos. Chem. Phys.

Discussion started: 5 May 2017

(c) Author(s) 2017. CC-BY 3.0 License.

Chemistry

and Physics

Discussions

(c) (i)

part of the flight, HALO flew at about $14 \mathrm{~km}$ altitude. The area covered by the observations includes highly variable ozone concentrations ranging from about $50 \mathrm{ppbv}$ in tropospheric air up to $600 \mathrm{ppbv}$ in stratospheric regions. In the northern part of the cross-section, tropospheric airmasses can be found in higher altitudes up to $11 \mathrm{~km}$ compared to $9 \mathrm{~km}$ in the southern part. Similarly, stratospheric airmasses reach lower altitudes in the southern part around $61.0^{\circ}$ to $62.0^{\circ}$ north. The resulting

5 horizontal gradient in ozone mixing ratio (compare Fig. 5b) as stratospheric tracer can be related to local exchanges between two airmasses at the location of the hexagon.

Additionally, the tomographic observations allowed the ozone assimilation to generate two distinct filaments of mainly stratospheric air reaching down to $12 \mathrm{~km}$ altitude in the analysis (Fig. 6b). In contrast to this, two tropospheric filaments were found in about 13 to $14 \mathrm{~km}$ height. The resulting horizontal variation of enhanced and reduced ozone concentrations compared to the background (Fig. 6a) leads to mixing-ratos ranging approximately from 260 to 460 ppbv in this region. These smallscale structures are typical indications for baroclinic folding activity well above the $2 \mathrm{PV}$ tropopause level. Their orientation towards higher tropopause altitudes in the northern part may indicate a connection to the horizontal airmass boundary which was observed in the horizontal synoptic-scale analysis (Fig. 5b).

\section{Conclusions}

Airborne limb-imaging retrievals from the GLORIA instrument offered the chance to analyze high-resolution remote-sensing data by chemical data assimilation. Its novel viewing geometry provides observations of the Ex-UTLS with an unprecedented resolution. By making tomographic observations, GLORIA demonstrated its ability to resolve large horizontal gradients in all directions.

Exploiting PV diagnostics, anisotropic and inhomogeneous background error correlations have been introduced into the assimilation system of EURAD-IM. This modification was able to elongate the spatial correlations parallel to significant horizontal gradients in PV as indicator of airmass boundaries. The combination of PV-dependent initialization and background error correlation has demonstrated the ability to optimize the chemical state of an airmass even if it is only partly observed. The following properties are preserved: Firstly, the qualitative shape of the airmass indicated by the meteorology is conserved, if this conforms with the assimilated observations. Secondly, the reconstruction of sharp gradients along an airmass boundaries is not only restricted to the observed locations. In case of a skillful meteorological forecast with a realistic representation of airmasses in the Ex-UTLS, these results appear to produce significant benefits by producing dynamically consistent analysis of trace gases. However, this doubled use of PV makes the result highly sensitive to errors in the meteorological forecast. This might become especially significant in case of phase errors of the meteorological forecast compared to the observations. The application of a meteorological ensemble might be an opportunity to quantify the uncertainty. An insight into potential influences of uncertainties in the meteorological forecast to the chemical state in the Ex-UTLS will be addressed in a follow-up paper (in preparation).

The tomographic observation pattern at the coast of Norway has underlined the ability of GLORIA to account for horizontal gradients around the tropopause. Upon assimilating this data, the ozone-analysis has shown its ability to produce extent and 
Atmos. Chem. Phys. Discuss., doi:10.5194/acp-2017-308, 2017

Manuscript under review for journal Atmos. Chem. Phys.

Discussion started: 5 May 2017

(C) Author(s) 2017. CC-BY 3.0 License.

(c) (i)
Atmospheric

Chemistry

and Physics

Discussions

orientation of filamentary foldings well above the tropopause. This analyzed features result from the closed tomographic observation and illustrates the ability of the assimilation system to reproduce small-scale variability indicated by GLORIA. Nevertheless, ozone and PV structures are not any more consistent after the chemistry-only assimilation. A coupled dynamicschemistry assimilation would be of avail.

These findings show the potential of chemical data assimilation to extend the knowledge of the composition of the ExUTLS covering a wider range of scales. PV-based influences in the assimilation of high-resolution remote-sensing data provide additional information about the spatial extent and alignment of airmasses as well as filaments.

However, in order to extract general knowledge about small-scale structures in the Ex-UTLS, an extended study assimilating more highly resolved limb-imaging observations is needed. The direct assimilation of observed radiances by GLORIA may lead to a further improvement of the resulting atmospheric state (e.g., Migliorini, 2011). Furthermore, additional assimilation of operational satellite-based or in situ observations would provide a larger coverage of observations.

\section{Code availability}

The code controlling the PV based covariance modeling is stored locally at the Rhenish Institute for Environmental Research as well as at the Jülich Supercomputer Centre (JSC) of Research Centre Jülich. It is available by request via email (he@ riu.unikoeln.de).

\section{Data availability}

The ozone retrievals from GLORIA measurements are available at the HALO database (https://halo-db.pa.op.dlr.de/). EURADIM ozone analysis and background fields are available from the author.

Acknowledgements. This work has been funded by the Helmholtz Climate Initiative REKLIM (Regional Climate Change), a joint research project of the Helmholtz Association of German research centers (HGF) under grant: REKLIM-2009-07-16. The authors gratefully acknowledge the computing time granted by the JARA-HPC Vergabegremium and VSR commission on the supercomputer JURECA (Jülich Supercomputing Centre, 2016) at Forschungszentrum Jülich. This work would not have been possible without the meteorological analysis for the initial values used in WRF, obtained from the NCEP's Global Forecasting System (GFS). A special thank go to all members of the GLORIA team especially to IEK-7 of Forschungzentrum Jülich for providing the observational data. 
Atmos. Chem. Phys. Discuss., doi:10.5194/acp-2017-308, 2017

Atmospheric

Chemistry

Discussion started: 5 May 2017

(c) Author(s) 2017. CC-BY 3.0 License.

and Physics

Discussions

(c) (i)

\section{References}

Bannister, R. N.: A review of forecast error covariance statistics in atmospheric variational data assimilation. II: Modelling the forecast error covariance statistics, Quarterly Journal of the Royal Meteorological Society, 134, 1971-1996, doi:10.1002/qj.340, http://dx.doi.org/10. 1002/qj.340, 2008.

5 Berre, L., Varella, H., and Desroziers, G.: Modelling of flow-dependent ensemble-based background-error correlations using a wavelet formulation in 4D-Var at Météo-France, Quarterly Journal of the Royal Meteorological Society, 141, 2803-2812, doi:10.1002/qj.2565, http://dx.doi.org/10.1002/qj.2565, 2015.

Bonavita, M., Hólm, E., Isaksen, L., and Fisher, M.: The evolution of the ECMWF hybrid data assimilation system, Quarterly Journal of the Royal Meteorological Society, 142, 287-303, doi:10.1002/qj.2652, http://dx.doi.org/10.1002/qj.2652, 2016.

Courtier, P.: Dual formulation of four-dimensional variational assimilation, Quarterly Journal of the Royal Meteorological Society, 123, 2449-2461, doi:10.1002/qj.49712354414, http://dx.doi.org/10.1002/qj.49712354414, 1997.

Danielsen, E. F.: Stratospheric-Tropospheric Exchange Based on Radioactivity, Ozone and Potential Vorticity, Journal of the atmospheric sciences, 25, 502-518, 1968.

Danielsen, E. F., Hipskind, R. S., Gaines, S. E., Sachse, G. W., Gregory, G. L., and Hill, G. F.: Three-dimensional analysis of potential vorticity associated with tropopause folds and observed variations of ozone and carbon monoxide, Journal of Geophysical Research: Atmospheres, 92, 2103-2111, doi:10.1029/JD092iD02p02103, http://dx.doi.org/10.1029/JD092iD02p02103, 1987.

Derber, J. and Rosati, A.: A Global Oceanic Data Assimilation System, Journal of Physical Oceanography, 19, 1333-1347, doi:10.1175/15200485(1989)019<1333:AGODAS>2.0.CO;2, http://dx.doi.org/10.1175/1520-0485(1989)019<1333:AGODAS>2.0.CO;2, 1989.

Douglass, A. R., Rood, R. B., Stolarski, R. S., Schoeberl, M. R., Proffitt, M. H., Margitan, J. J., Loewenstein, M., Podolske, J. R., and Strahan, S. E.: Global three-dimensional constituent fields derived from profile data, Geophysical Research Letters, 17, 525-528, doi:10.1029/GL017i004p00525, http://dx.doi.org/10.1029/GL017i004p00525, 1990.

Elbern, H., Strunk, A., Schmidt, H., and Talagrand, O.: Emission rate and chemical state estimation by 4-dimensional variational inversion, Atmospheric Chemistry and Physics, 7, 3749-3769, doi:10.5194/acp-7-3749-2007, http://www.atmos-chem-phys.net/7/3749/2007/, 2007.

Elbern, H., Schwinger, J., and Botchorishvili, R.: Chemical state estimation for the middle atmosphere by four-dimensional variational data assimilation: System configuration, Journal of Geophysical Research, 115, D06 302+, doi:10.1029/2009jd011953, http://dx.doi.org/10. 1029/2009jd011953, 2010.

Emili, E., Barret, B., Massart, S., Le Flochmoen, E., Piacentini, A., El Amraoui, L., Pannekoucke, O., and Cariolle, D.: Combined assimilation of IASI and MLS observations to constrain tropospheric and stratospheric ozone in a global chemical transport model, Atmospheric Chemistry and Physics, 14, 177-198, doi:10.5194/acp-14-177-2014, http://www.atmos-chem-phys.net/14/177/2014/, 2014.

Errera, Q., Daerden, F., Chabrillat, S., Lambert, J. C., Lahoz, W. A., Viscardy, S., Bonjean, S., and Fonteyn, D.: 4D-Var assimilation of MIPAS chemical observations: ozone and nitrogen dioxide analyses, Atmospheric Chemistry and Physics, 8, 6169-6187, doi:10.5194/acp-8-61692008, http://www.atmos-chem-phys.net/8/6169/2008/, 2008.

Fischer, H., Birk, M., Blom, C., Carli, B., Carlotti, M., Clarmann, T. v., Delbouille, L., Dudhia, A., Ehhalt, D., Endemann, M., et al.: MIPAS: an instrument for atmospheric and climate research, Atmospheric Chemistry and Physics, 8, 2151-2188, 2008.

Gettelman, A., Hoor, P., Pan, L. L., Randel, W. J., Hegglin, M. I., and Birner, T.: The extratropical upper troposphere and lower stratosphere, REVIEWS OF GEOPHYSICS, 49, 2011. 
Atmos. Chem. Phys. Discuss., doi:10.5194/acp-2017-308, 2017

Manuscript under review for journal Atmos. Chem. Phys.

Discussion started: 5 May 2017

(C) Author(s) 2017. CC-BY 3.0 License.
Atmospheric

Chemistry

and Physics

Discussions

Hamill, T. M., Whitaker, J. S., and Snyder, C.: Distance-dependent filtering of background error covariance estimates in an ensemble Kalman filter, Monthly Weather Review, 129, 2776-2790, 2001.

Hass, H.and Jakobs, H. J. and Memmesheimer, M.: Analysis of a regional model (EURAD) near surface gas concentration predictions using observations from networks, Meteorology and Atmospheric Physics, 57, 173-200, doi:10.1007/BF01044160, http://dx.doi.org/10.1007/ BF01044160, 1995.

Hoskins, B. J., McIntyre, M. E., and Robertson, A. W.: On the use and significance of isentropic potential vorticity maps, Quarterly Journal of the Royal Meteorological Society, 111, 877-946, doi:10.1002/qj.49711147002, http://dx.doi.org/10.1002/qj.49711147002, 1985.

Jülich Supercomputing Centre: JURECA: General-purpose supercomputer at Jülich Supercomputing Centre, Journal of large-scale research facilities, 2, doi:10.17815/jlsrf-2-121, http://dx.doi.org/10.17815/jlsrf-2-121, 2016.

10 Kalnay, E.: Atmospheric Modeling, Data Assimilation and Predictability, Cambridge University Press, New York, 2003.

Kalnay, E., Kanamitsu, M., Kistler, R., Collins, W., Deaven, D., Gandin, L., Iredell, M., Saha, S., White, G., Woollen, J., Zhu, Y., Leetmaa, A., Reynolds, R., Chelliah, M., Ebisuzaki, W., Higgins, W., Janowiak, J., Mo, K. C., Ropelewski, C., Wang, J., Jenne, R., and Joseph, D.: The NCEP/NCAR 40-Year Reanalysis Project, Bulletin of the American Meteorological Society, 77, 437-471, doi:10.1175/15200477(1996)077<0437:TNYRP>2.0.CO;2, http://dx.doi.org/10.1175/1520-0477(1996)077<0437:TNYRP>2.0.CO;2, 1996.

Kaufmann, M., Blank, J., Guggenmoser, T., Ungermann, J., Engel, A., Ern, M., Friedl-Vallon, F., Gerber, D., Grooß, J. U., Guenther, G., Höpfner, M., Kleinert, A., Kretschmer, E., Latzko, T., Maucher, G., Neubert, T., Nordmeyer, H., Oelhaf, H., Olschewski, F., Orphal, J., Preusse, P., Schlager, H., Schneider, H., Schuettemeyer, D., Stroh, F., Suminska-Ebersoldt, O., Vogel, B., M. Volk, C., Woiwode, W., and Riese, M.: Retrieval of three-dimensional small-scale structures in upper-tropospheric/lower-stratospheric composition as measured by GLORIA, Atmospheric Measurement Techniques, 8, 81-95, doi:10.5194/amt-8-81-2015, http://www.atmos-meas-tech.net/8/81/2015/, 2015.

Lahoz, W., Khattatov, B., and Menard, R.: Data Assimilation - Making Sense of Observations, Springer, Heidelberg, 2010.

Lary, D. J., Chipperfield, M. P., Pyle, J. A., Norton, W. A., and Riishøjgaard, L. P.: Three-dimensional tracer initialization and general diagnostics using equivalent PV latitude-potential-temperature coordinates, Quarterly Journal of the Royal Meteorological Society, 121, 187-210, doi:10.1002/qj.49712152109, http://dx.doi.org/10.1002/qj.49712152109, 1995.

Liu, D. C. and Nocedal, J.: On the limited memory BFGS method for large scale optimization, Mathematical Programming, 45, 503-528, doi:10.1007/BF01589116, http://dx.doi.org/10.1007/BF01589116, 1989.

Lorenc, A. C.: Optimal nonlinear objective analysis, Quarterly Journal of the Royal Meteorological Society, 114, 205-240, doi:10.1002/qj.49711447911, http://dx.doi.org/10.1002/qj.49711447911, 1988.

Migliorini, S.: On the Equivalence between Radiance and Retrieval Assimilation, Monthly Weather Review, $140,2011$.

Offermann, D., Grossmann, K.-U., Barthol, P., Knieling, P., Riese, M., and Trant, R.: Cryogenic Infrared Spectrometers and Telescopes for the Atmosphere (CRISTA) experiment and middle atmosphere variability, Journal of Geophysical Research: Atmospheres, 104, 16311$16325,1999$.

Parrish, D. F. and Derber, J. C.: The National Meteorological Center's spectral statistical-interpolation analysis system, Monthly Weather Review, 120, 1747-1763, 1992.

35 Prather, M. J., Zhu, X., Flynn, C. M., Strode, S. A., Rodriguez, J. M., Steenrod, S. D., Liu, J., Lamarque, J.-F., Fiore, A. M., Horowitz, L. W., Mao, J., Murray, L. T., Shindell, D. T., and Wofsy, S. C.: Global Atmospheric Chemistry - Which Air Matters, Atmospheric Chemistry and Physics Discussions, 2017, 1-40, doi:10.5194/acp-2016-1105, http://www.atmos-chem-phys-discuss.net/acp-2016-1105/, 2017. 
Atmos. Chem. Phys. Discuss., doi:10.5194/acp-2017-308, 2017

Manuscript under review for journal Atmos. Chem. Phys.

Discussion started: 5 May 2017

(C) Author(s) 2017. CC-BY 3.0 License.
Atmospheric

Chemistry

and Physics

Discussions

(c) (i)

Rawlins, F., Ballard, S. P., Bovis, K. J., Clayton, A. M., Li, D., Inverarity, G. W., Lorenc, A. C., and Payne, T. J.: The Met Office global four-dimensional variational data assimilation scheme, Quarterly Journal of the Royal Meteorological Society, 133, 347-362, doi:10.1002/qj.32, http://dx.doi.org/10.1002/qj.32, 2007.

Riese, M., Ploeger, F., Rap, A., Vogel, B., Konopka, P., Dameris, M., and Forster, P.: Impact of uncertainties in atmospheric mixing on simulated UTLS composition and related radiative effects, Geophysical research abstracts, 15, EGU2013-3295-1, http://juser.fz-juelich. de/record/133697, 2013.

Riese, M., Oelhaf, H., Preusse, P., Blank, J., Ern, M., Friedl-Vallon, F., Fischer, H., Guggenmoser, T., Höpfner, M., Hoor, P., Kaufmann, M., Orphal, J., Plöger, F., Spang, R., Suminska-Ebersoldt, O., Ungermann, J., Vogel, B., and Woiwode, W.: Gimballed Limb Observer for Radiance Imaging of the Atmosphere (GLORIA) scientific objectives, Atmospheric Measurement Techniques, 7, 1915-1928, doi:10.5194/amt7-1915-2014, http://www.atmos-meas-tech.net/7/1915/2014/, 2014.

Riishøjgaard, L.: A direct way of specifying flow-dependent background error correlations for meteorological analysis systems, Tellus series A-dynamic meteorology ans oceanography, 50A, 42-57, 1998.

Riishøjgaard, L. P.: On four-dimensional variational assimilation of ozone data in weather-prediction models, Quarterly Journal of the Royal Meteorological Society, 122, 1545-1571, doi:10.1002/qj.49712253505, http://dx.doi.org/10.1002/qj.49712253505, 1996.

Riishøjgaard, L. P. and Källen, E.: On the correlation between ozone and potential vorticity for large-scale Rossbywaves, Journal of Geophysical Research, 102, 8793-8804, 1997.

Skamarock, W. C., Klemp, J. B., Dudhia, J., Gill, D. O., Barker, D. M., Wang, W., and Powers, J. G.: A Description of the Advanced Research WRF Version 2, NCAR technical note, 2005.

Talagrand, O. and Courtier, P.: Variational assimilation of meteorological observations with the adjoint vorticity equation. I: Theory, Quarterly

Journal of the Royal Meteorological Society, 113, 1311-1328, doi:10.1002/qj.49711347812, 1987.

Ungermann, J., Blank, J., Lotz, J., Leppkes, K., Hoffmann, L., Guggenmoser, T., Kaufmann, M., Preusse, P., Naumann, U., and Riese, M.: A 3-D tomographic retrieval approach with advection compensation for the air-borne limb-imager GLORIA, Atmospheric Measurement Techniques, 4, 2509-2529, doi:10.5194/amt-4-2509-2011, http://www.atmos-meas-tech.net/4/2509/2011/, 2011.

Ungermann, J., Blank, J., Dick, M., Ebersoldt, A., Friedl-Vallon, F., Giez, A., Guggenmoser, T., Höpfner, M., Jurkat, T., Kaufmann, M., Kaufmann, S., Kleinert, A., Krämer, M., Latzko, T., Oelhaf, H., Olchewski, F., Preusse, P., Rolf, C., Schillings, J., Suminska-Ebersoldt, O., Tan, V., Thomas, N., Voigt, C., Zahn, A., Zöger, M., and Riese, M.: Level 2 processing for the imaging Fourier transform spectrometer GLORIA: derivation and validation of temperature and trace gas volume mixing ratios from calibrated dynamics mode spectra, Atmospheric Measurement Techniques, 8, 2473-2489, doi:10.5194/amt-8-2473-2015, http://www.atmos-meas-tech.net/8/2473/2015/, 2015.

Waters, J. W., Froidevaux, L., Harwood, R. S., Jarnot, R. F., Pickett, H. M., Read, W. G., Siegel, P. H., Cofield, R. E., Filipiak, M. J., Flower,

D. A., et al.: The earth observing system microwave limb sounder (EOS MLS) on the Aura satellite, IEEE Transactions on Geoscience and Remote Sensing, 44, 1075-1092, 2006.

Weaver, A. and Courtier, P.: Correlation modelling on the sphere using a generalized diffusion equation, Quarterly Journal of the Royal Meteorological Society, 127, 1815-1846, doi:10.1002/qj.49712757518, http://dx.doi.org/10.1002/qj.49712757518, 2001. 